\title{
METACOGNITIVE ACCURACY AND LEARNING TO LEARN: A DEVELOPMENTAL PERSPECTIVE
}

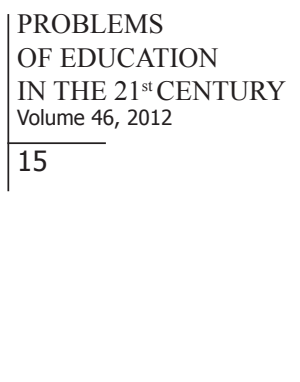

Karin Bakracevic Vukman
University of Maribor, Slovenia
E-mail: karin.bakracevic@um.si

Abstract

Metacognition belongs to higher-order mental processes and enables us to control, plan and accordingly regulate our own learning and problem solving process. In the present study we researched developmental changes in different reasoning domains and in metacognitive accuracy, which is considered as part of successful metacognitive monitoring/regulation, and as an essential element of self-regulated learning and learning to learn competence.

The study involved 282 participants from four different age groups: 13-15-, 23-25-, 33-35- and 43-45year olds. These participants solved tasks addressed to spatial, verbal-propositional and social reasoning, and evaluated their own performance on these tasks. To specify possible differences in metacognitive accuracy, the metacognitive accuracy index was computed.

Results showed that metacognitive evaluations were accurate in spatial domain, less accurate in verbalpropositional and quite inaccurate in the social domain. The accuracy of self-evaluation increased with age and males were more accurate in their self-evaluations than females. Improvement of metacognitive accuracy with age is in tune with findings that metacognition becomes more effective with development and that people with age become more reflective and self-aware.

Key words: reasoning, metacognition, metacognitive accuracy, self-regulated learning.

\section{Introduction}

Looking from the perspective of cognitive and developmental psychology learning to learn could be viewed as attaining cognitive/ metacognitive, motivational and emotional selfregulation. Thus, metacognition can be considered as an important building block of learning to learn.

Metacognition belongs to higher-order mental processes and enables us to control and plan our own mental activities (also to control one's own learning process). It leads us in selection and evaluation of cognitive tasks, in detection of mistakes in the problem-solving or learning process, in choosing goals and adequate problem solving/ learning strategies.

Structure of metacognition (acc. to Flavell, 1979):
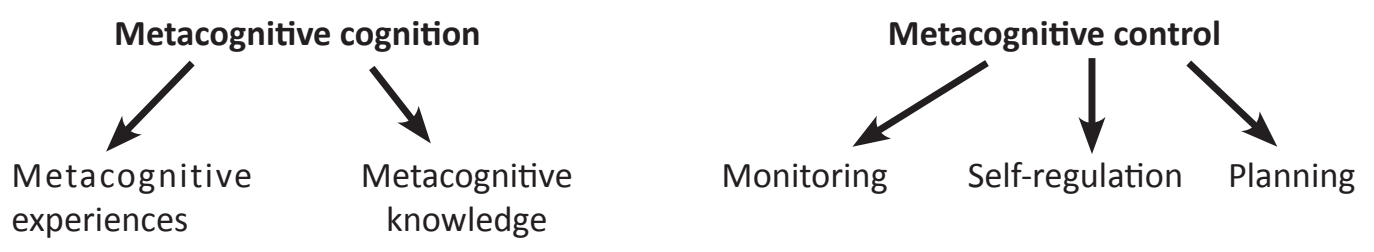
PROBLEMS

OF EDUCATION

IN THE $21^{\text {st }}$ CENTURY

Volume 46, 2012

Metacognitive knowledge consists of three components: (1) knowledge of self (e.g., knowing about my strong and weak points); (2) knowledge of task; (3) knowledge of strategies (also when and how to use them).

\section{Development of Metacognition}

At about the age of eight years, children start to be able to differentiate between cognitive functions, they start to have a self-concept that involves taxonomic self-descriptions, generally positive and often inaccurate. In adolescence, self-awareness gradually develops, the self-concept becomes dimensionalized and generally accurate, and problem solving becomes planfull and systematic. Students start to be able to differentiate between the cognitive processes involved in different kinds of activities, they know where they are strong and where they are weak, and they can plan their problem solving activities (Demetriou, 2004; Demetriou \& Bakracevic, 2009). Furthermore, many researchers of cognitive development argue that, with age, persons become more reflective and self-aware (Bakracevic Vukman, 2005; Bakracevic \& Demetriou, 2005; Kuhn, 2000). As a result, they become more able than younger persons to monitor and regulate their cognitive functioning. In accordance with this tendency, accuracy of metacognitive statements and evaluations is expected to improve through early and mature adulthood.

\section{Metacognition, Self-regulated Learning and Learning to Learn}

Models of self-regulated learning provide a theoretical framework for understanding the role of metacognition in learning. There is considerable research documenting metacognition as an essential ingredient of self-directed and self-regulated learning (Cao \& Nietfeld, 2005). Results also show that students who observe and evaluate their performance accurately can react appropriately by keeping or changing their study strategies to achieve optimal study results (Hartman, 2001). Moreover, Cao and Nietfield (2005) suggest that the ability to accurately judge the status of learning and problem solving enables students to become strategic and effective in the learning process. The superior monitoring accuracy produces more effective metacognitive self-regulation.

Our research was mainly focused on developmental aspects of metacognitive monitoring accuracy. In the present study we researched developmental changes in metacognitive accuracy in different reasoning domain, especially accuracy of metacognitive self-evaluations from adolescence to middle age.

\section{Methodology of Research}

\section{Participants}

The research included 282 participants from four age groups: adolescents (13 to 15 years old); younger adults between 23 and 25 years; adults, 33 to 35 years; and adults 43 to 45 years of age. The first group included 42 pupils, 22 boys and 20 girls, each of the next three age groups comprised an equal number of participants (40) with university education (in the second group there were the students) and with primary school or vocational education. Both genders were equally represented within all six adult subgroups. 


\section{Instruments}

All participants have been tested by the following tasks and questionnaires:

Reasoning: the protocol with tasks related to the domain of spatial reasoning, verbal/ logical reasoning and social reasoning (Demetriou in Kazi, 2001). From each domain the three tasks of increasing difficulty level have been chosen.

The meta-cognitive self-evaluation of achievement: after solving each of nine tasks, the participants were asked to evaluate their performance in reference to a seven-point scale. The question was: How satisfied are you with your solution of the task? Please mark the adequacy and the correctness of the solution on a seven-point scale (the answers could vary from 1 - absolutely incorrect to 7 - absolutely correct). This self-evaluation performance resembles the measures used by other scholars studying the relations between actual cognitive attainment and related subjective evaluation of performance (Kleitman \& Stankov, 2007)

\section{Procedure}

The testing has been carried out in groups. Each participant was given a protocol with nine tasks from three reasoning domains and the instruction to evaluate on the scale the adequacy of his/her solution after solving a problem/ task.

To get better insight into accuracy of metacognitive evaluations, a new variable has been created: Index of Metacognitive Accuracy. As an accurate self-evaluation a condition has been defined, when the correct solution corresponded with the evaluation score 6 or 7 (on the seven level scale) and when the incorrect solution of the task corresponded with the evaluation score 0 or 1 . Any other combination of the achievement and self-evaluation was counted as incorrect. For the correct evaluation of each task the test person was given a point. This way we calculated IMA for each reasoning domain and the total IMA.

MANOVA (multivariate analysis of variance) has been performed to check the effects of age, gender and reasoning domain on the metacognitive accuracy.

To recognize closer the reasons for differences in the metacognitive accuracy the participants have been, in respect of the metacognitive self-evaluation, ranged into the following categories:

(-2)... strict incorrect: in case that the correct answer is evaluated with 1 or 2

(-1)... strict uncertain: in case that the correct answer is evaluated with 3,4 or 5

(0)... correct: in case that the correct answer is evaluated with 6 or 7 and the incorrect answer with 1 or 2 ;

(1)... lenient uncertain: in case that the incorrect answer is evaluated with 3,4 or 5;

(2)... lenient incorrect: in case that the incorrect answer is evaluated with 6 or 7

Qualitative analysis has been performed and arrangement of the participants into the mentioned groups due to age and gender is shown in the tables 1 and 2 .

\section{Results of Research}

Firstly, an analysis (MANOVA) on IMA has been performed: 4 (four age groups) x 2 (gender) $\mathrm{x} 3$ (three domains). The effect of age has shown as statistically significant $(\mathrm{F}(3,274)$ $=5.88, \mathrm{p}=0.001)$, equally the effect of gender $(\mathrm{F}(1,274)=4.99, \mathrm{p}=0.026)$ and the effect of the reasoning domain $(\mathrm{F}(2,273)=27.28, \mathrm{p}=0.0001)$. As shown in the figure 1 , the correctness of the metacognitive evaluations systematically increases with age, especially from adolescence to middle adulthood (adult group 1). As for the gender, the analysis has shown that men tend to be more accurate in self evaluations as women. The accuracy of evaluations is the best in 
PROBLEMS OF EDUCATION IN THE $21^{\text {st }}$ CENTURY Volume 46, 2012

the spatial domain, a little bit worse in the verbal-logical and the worst in the social reasoning domain.

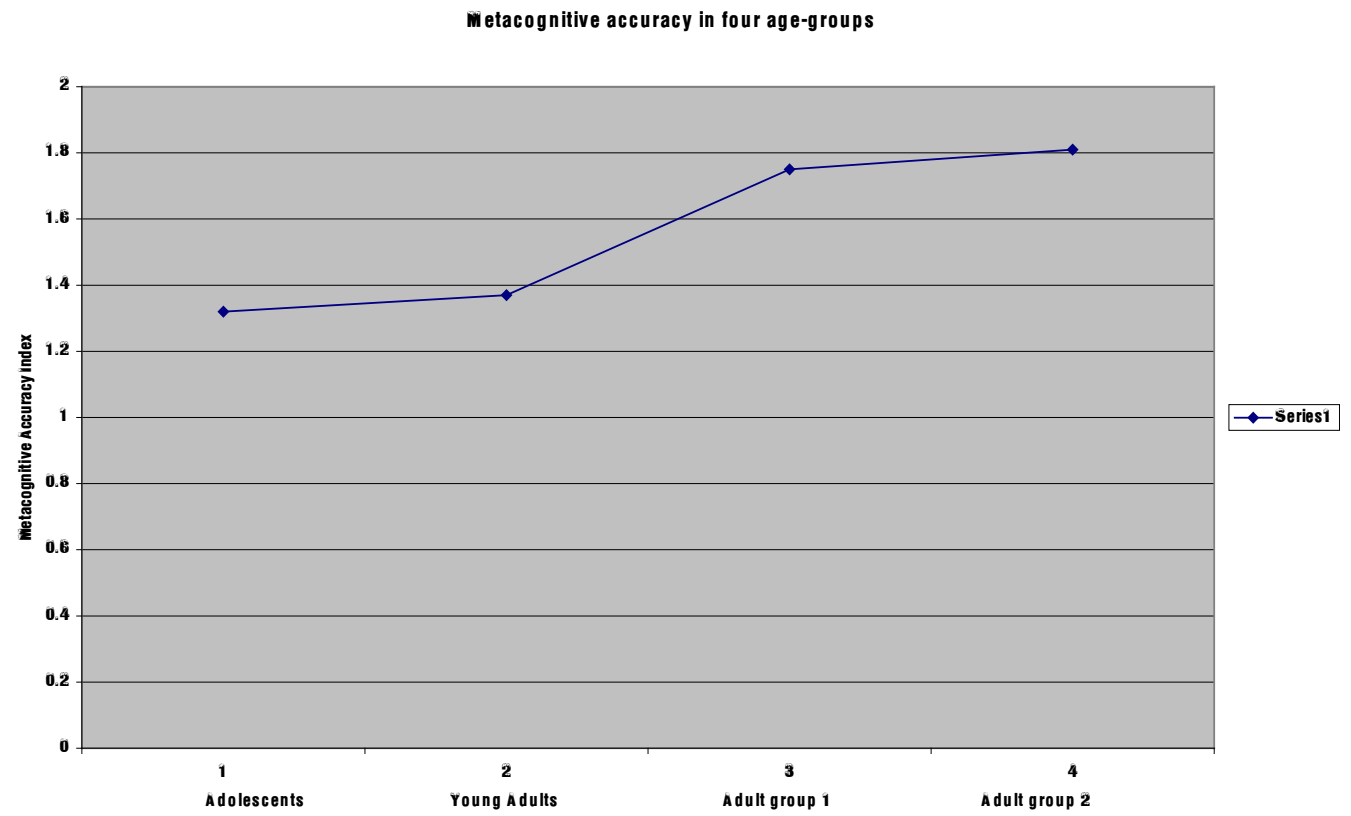

Figure 1: Metacognitive accuracy in four age groups.

Table 1. Distribution of participants in categories according to metacognitive self-evaluations in different reasoning domains- comparison between age-groups.

\begin{tabular}{|c|c|c|c|c|c|c|c|c|c|c|c|c|}
\hline & \multicolumn{2}{|c|}{ Younger adults } & \multicolumn{3}{c|}{ Adult group 1 } & \multicolumn{3}{c|}{ Adult group 2 } & \multicolumn{3}{c|}{ Total N } \\
\cline { 2 - 15 } $\begin{array}{c}\text { Cate- } \\
\text { gory }\end{array}$ & $\begin{array}{c}\text { Spa- } \\
\text { tial }\end{array}$ & $\begin{array}{c}\text { Ver- } \\
\text { bal }\end{array}$ & $\begin{array}{c}\text { So- } \\
\text { cial }\end{array}$ & $\begin{array}{c}\text { Spa- } \\
\text { tial }\end{array}$ & Verbal & Social & $\begin{array}{c}\text { Spa- } \\
\text { tial }\end{array}$ & $\begin{array}{c}\text { Ver- } \\
\text { bal }\end{array}$ & $\begin{array}{c}\text { So- } \\
\text { cial }\end{array}$ & $\begin{array}{c}\text { Spa- } \\
\text { tial }\end{array}$ & $\begin{array}{c}\text { Ver- } \\
\text { bal }\end{array}$ & $\begin{array}{c}\text { So- } \\
\text { cial }\end{array}$ \\
\hline-2 & 5 & 3 & 2 & 1 & 1 & 0 & 1 & 4 & 0 & 7 & 8 & 2 \\
\hline-1 & 48 & 68 & 23 & 25 & 41 & 27 & 27 & 41 & 30 & 100 & 150 & 80 \\
\hline 0 & 116 & 87 & 44 & 154 & 103 & 66 & 132 & 100 & 85 & 402 & 290 & 195 \\
\hline 1 & 41 & 52 & 86 & 32 & 58 & 53 & 38 & 47 & 36 & 111 & 157 & 175 \\
\hline 2 & 30 & 30 & 85 & 28 & 37 & 94 & 42 & 48 & 89 & 100 & 115 & 268 \\
\hline $\mathrm{N}$ & 240 & 240 & 240 & 240 & 240 & 240 & 240 & 240 & 240 & 720 & 720 & 720 \\
\hline
\end{tabular}

Note: -2: strict incorrect; -1: strict uncertain; 0: correct; 1: lenient uncertain; 2: lenient incorrect 
Table 2. Distribution of participants in categories according to metacognitive self-evaluations in different reasoning domains- comparison between genders.

\begin{tabular}{|c|c|c|c|c|c|c|c|c|c|}
\hline \multirow{2}{*}{ Category } & \multicolumn{3}{|c|}{ Males } & \multicolumn{3}{c|}{ Females } & \multicolumn{3}{c|}{ Total N } \\
\cline { 2 - 10 } & Spatial & Verbal & $\begin{array}{c}\text { So- } \\
\text { cial }\end{array}$ & Spatial & Verbal & Social & Spatial & Verbal & Social \\
\hline-2 & 7 & 9 & 2 & 3 & 6 & 2 & 10 & 15 & 4 \\
\hline-1 & 45 & 77 & 44 & 78 & 106 & 44 & 123 & 183 & 88 \\
\hline 0 & 250 & 177 & 112 & 218 & 154 & 105 & 468 & 331 & 217 \\
\hline 1 & 54 & 89 & 105 & 76 & 95 & 116 & 130 & 184 & 221 \\
\hline 2 & 64 & 68 & 157 & 51 & 65 & 159 & 115 & 133 & 316 \\
\hline N & 420 & 420 & 420 & 426 & 426 & 426 & 846 & 846 & 846 \\
\hline
\end{tabular}

\section{Discussion}

Although self-evaluations of achievement reflect to a great extent the actual results, it is possible to conclude that, comparing different age groups, developmental differences in the actual achievements differ from differences in the self-evaluation scores. In accordance with this, it is possible to assume that the evaluation of the task solutions does not reflect quite accurately the actual performance. Thus we were interested in discovering how and why the accuracy of self-evaluations changes with the development. The analysis of the index of metacognitive accuracy has shown that the accuracy of self-evaluations systematically increases with age, especially from adolescence to middle adulthood. There are also significant differences between genders, showing that men tend to be more accurate in the evaluation of their achievements. It shows also that self-evaluations are most accurate in the spatial, followed by the verbal and at least accurate in the social reasoning domain. This result could be explained with higher transparency of the spatial domain, which would mean above all clear criteria of the solution adequacy, whilst the problems from the social domain are mostly ill-defined and it is more difficult to estimate the level of adequacy of the reached solution. The increase of the accuracy of metacognitive evaluations with age indicates that people become with development throughout their adulthood more self-reflexive and "inner oriented" (Labouvie-Vief, 1995) and that the metacognition becomes more and more effective (Kuhn, 2000). The qualitative analysis of the accuracy of metacognitive self-evaluations helps to explain the tendencies mentioned above. It has shown that the lower accuracy of self-evaluations with younger adults and women derives from too much criticism to own achievements, as much more than in other age groups and among the male participants resp., perceived and evaluated their cognitive achievements in a way which was defined as "strict uncertain" (see Tables 1 and 2). Two older adult groups have higher frequency in the category "correct" - mainly in the verbal-logical domain, the middle adult group is the most accurate of all in the evaluation of the tasks in spatial reasoning, and the mature adults are the best in the metacognitive accuracy in the social reasoning domain, although it shows that in this field all age groups tend to overestimate their own achievements, which reflects in high frequencies within the evaluating category »lenient incorrect«. Accordingly it is possible to say that there is a general tendency to overestimate the quality of solutions gained on solving the social reasoning tasks. The researches, engaged in structure and development of metacognitive evaluations (Demetriou in Kazi, 2001) show mainly that these evaluations to great extent reflect actual achievements, however there are other variables influencing them, such as cognitive self-image, self-efficacy beliefs (Bandura, 1989) and other, also non-cognitive variables. Regarding the differences between sexes, the results agree with 
PROBLEMS

OF EDUCATION

IN THE $21^{\text {st }}$ CENTURY

Volume 46, 2012

the previous researches that women tend to underestimate their own achievements (Philips and Zimmerman, 1990). In our study this tendency has shown in spatial and verbal-logical domain and not in the social domain, although there is to perceive that besides the tendency to underestimate the achievements the reason for lower accuracy is also uncertainty. Namely, by analyzing the frequency distributions it can be seen that females have higher frequencies in the category »strict uncertain « as well as in the category "lenient uncertain". Thus, a review of the arrangements due to categories indicates that women avoided extreme evaluations (i.e. the estimation »my solution is perfectly correct«) and this tendency could be the origin of lower metacognitive accuracy. Lower accuracy of metacognitive evaluations in adolescents and younger adults is probably at least partly dependent on developmental characteristics, as the period of younger adulthood, included into the research, means the entering structure of adulthood, thus as a transition period requires adapting to new demands and criteria that should be characteristic for adulthood.

\section{Conclusions}

The results have shown improvement in metacognitive accuracy from adolescence through the adult years. The most significant difference is acquired between adolescence and middle adulthood. Because accuracy of metacognitive monitoring and self-evaluation are part of successful self-regulation of learning, we could start with developing better self-regulation skills already before and during adolescence. For example, providing quality feedback on the student performance (also to give the pupils options for self-assessment) can improve pupils' ability to accurately monitor and evaluate their learning and problem solving process.

\section{References}

Bakracevic Vukman, K. (2005). Developmental differences in metacognition and their connections with cognitive development in adulthood. Journal of Adult Development, 12 (4), 211-221.

Bakracevic, K., \& Demetriou, A. (2005). Developmental differences in accuracy of metacognitive evaluations during adulthood. In: Constantinou, C. P. (Ed.) Multiple perspectives on effective learning environments, Abstracts: Biennial Meeting of European Association for Research on Learning and Instruction, pp. 1053-1054.

Bandura, A. (1989). Regulation of cognitive processes through perceived self-efficacy. Developmental Psychology, 25 (5), 729-735.

Cao, L., \& Nietfeld, L. J. (2005). Judgment of Learning, Monitoring Accuracy, and Student Performance in the Classroom Context. Current Issues in Education, [On-line], 8 (4). Retrieved from: http://cie. ed.asu.edu/volume8/number4/

Demetriou, A. (2004). Mind, intelligence and development: A cognitive, differential, and developmental theory of intelligence. In A. Demetriou \& A. Raftopoulos, (Eds.), Cognitive developmental change: Models, methods, and measurement (pp. 21-73) Cambridge: Cambridge University Press.

Demetriou, A., \& Bakracevic, K. (2009). Reasoning and self-awareness from adolescence to middle age: Organization and development as a function of education. Learning and Individual Differences, 19 (2), 181-194.

Demetriou, A., \& Kazi, S. (2001). Unity and modularity in the mind and the self: Studies on the relationships between self-awareness, personality, and intellectual development from childhood to adolescence. London: Routledge.

Flavell, J. H. (1979). Metacognition and cognitive monitoring. A new area of developmental inquiry. American Psychologist, 34 (10), 906-911.

Hartman, H. J. (2001). Metacognition in learning and instruction: Theory research and practice. Amsterdam: Kluwer Academic Publishers. 
Kleitman, S., \& Stankov, L. (2007). Self-confidence and metacognitive processes. Learning and Individual Differences, 17 (2), 161-173.

Kuhn, D. (2000). Metacognitive development. Current Directions in Psychological Science, 9 (5), 178 181.

Labouvie-Vief, G., Chiodo, L. M., Gougen, L. A., Diehl, M., \& Orwoll, L. (1995). Representations of self across the life span. Psychology and Aging, 10 (3), 404-415.

Phillips, D. A., \& Zimmerman, M. (1990). The developmental course of perceived competence and incompetence among competent children. In: R. J. Sternberg \& J. Kolligian (Eds.), Competence considered (pp. 41-66), New Haven: Yale University Press.

Pintrich, P. R. (2000). The role of goal orientation in self-regulated learning. In M. Boekaerts, P. R. Pintrich \& M. Zeidner (Eds.), Handbook of self-regulation (pp. 451-502), New York: Academic Press.

Advised by Boris Aberšek, University of Maribor, Slovenia

Received: May 12, 2012

Accepted: July 20, 2012

Karin Bakracevic Vukman PhD, Professor of Psychology, Department of Psychology, Faculty of Arts, University of Maribor, Koroska 160, 2000 Maribor, Slovenia.

E-mail: karin.bakracevic@um.si 